\title{
Quem são os diplomados a distância em regiões não-metropolitanas do Brasil? Um estudo de caso do curso de administração a distância da Universidade Federal de Santa Catarina
}

\author{
Who are the distance graduates in non-metropolitan regions of \\ Brazil? A case study in the distance management course of the \\ Federal University of Santa Catarina
}

\author{
Karin Vieira da Silva ${ }^{1}$, João Peixoto ${ }^{2}$, Anderson Sasaki Vasques Pacheco ${ }^{3}$
}

\section{Resumo}

O presente estudo tem como objetivo analisar o perfil dos diplomados em regiões não-metropolitanas do Brasil. Para a concretização desse objetivo, utilizou-se o recorte do curso a distância de graduação em administração da Universidade Federal de Santa Catarina, nas cidades do interior do Rio Grande do Sul e de Santa Catarina. Quanto aos procedimentos metodológicos, essa pesquisa pode ser classificada como um levantamento e utilizou dados quantitativos. Para a recolha de dados utilizou-se o questionário como ferramenta e a análise foi feita por meio da descrição de dados estatísticos. Como principais resultados, verificou-se que os alunos possuem um perfil distinto dos estudantes de cursos presenciais, sendo formado por pessoas com uma condição familiar e profissional mais avançada. Outra questão a ser ressaltada é que os alunos não possuíam ensino superior antes de entrar no curso a distância oferecido pela UFSC. Esses dados dão indicativos de que a educação a distância cumpre, neste contexto, a função de atender um público que, por diferentes motivos, não consegue aceder ao ensino superior presencial, e pode, desta forma, contribuir para o desenvolvimento de regiões interioranas do país.

Palavras-chave: Perfil dos egressos. Educação a distância. Universidade aberta.

\begin{abstract}
The following study aims to analyze the graduates characteristics in Brazilian non-metropolitan regions. In order to achieve this objective, it was defined as study object, the management distance education course of Federal University of Santa Catarina, in the inner cities of Rio Grande do Sul and Santa Catarina. Regarding the methodological procedures, this research was classified as a survey and used quantitative data. For data gathering, the questionnaire tool was used and the analysis was done with descriptive statistics data. As main results, it was verified that the distance education students

\footnotetext{
${ }^{1}$ Doutora em Sociologia Econômica e das Organizações pelo Instituto Superior de Economia e Gestão da Universidade de Lisboa. É investigadora associada do Instituto Superior de Economia e Gestão da Universidade de Lisboa e participa de projetos de pesquisa na Universidade Federal de Santa Catarina. E-mail: vieira.karin@gmail.com

2 Professor Catedrático no Instituto Superior de Economia e Gestão da Universidade de Lisboa (ISEG/ULisboa) Investigador do SOCIUS/CSG - Centro de Investigação em Sociologia Económica e das Organizações, ISEG/ULisboa

3 Doutor em Sociologia Econômica e das Organizações pelo Instituto Superior de Economia e Gestão da Universidade de Lisboa. Pesquisador no ISEG no grupo de Sociologia Econômica das Organizações - SOCIUS - da Universidade de Lisboa. E-mail: sasaki.anderson@gmail.com
} 
have distinct characteristics comparing with classroom academics, being formed by people with more advanced family and occupation conditions. Another issue to be emphasized is that, for most of the students that was the first time in a university. These data give indications that distance education fulfills, in this context, the function to get an audience that, for different reasons, cannot access higher education, and thus, can contribute to the development in the countryside.

Keywords: Graduates profile. Distance education. Open university.

\section{Introdução}

A análise do perfil geral de estudantes em educação a distância (EaD) no Brasil é conduzida por um grande estudo denominado "Censo EaD.BR", da Associação Brasileira de Educação a Distância [ABED] (ASSOCIAÇÃO BRASILEIRA DE EDUCAÇÃO A DISTÂNCIA, 2015). Entretanto, há outros estudos que também analisam o perfil dos alunos em $\mathrm{EaD}$, mas por meio de diferentes critérios, como o ambiente virtual de aprendizagem (FERREIRA; MENDONÇA; MENDONÇA, 2007), aluno evadido (PACHECO et al., 2011) e curso oferecido (PEREIRA; PACHECO; FIATES, 2013). No entanto, nenhum desses estudos teve o intuito de analisar o perfil do aluno em locais onde o acesso à educação é potencialmente mais dificultado, como é o caso de regiões interioranas do Brasil.

Rodriguez e Caro (2002) ressaltam que um dos principais objetivos da educação a distância, especialmente em países com vastos territórios, é o de proporcionar o acesso à educação superior em locais distantes de grandes centros urbanos, democratizando o ensino para populações que não poderiam ter acesso à Universidades.

No Brasil, uma das iniciativas mais conhecidas que vão nesse sentido é a Universidade Aberta do Brasil. Segundo Pereira, Pacheco e Fiates (2013), o interesse em democratizar o ensino pode ser identificado na política da Universidade Aberta do Brasil, que ampliou o acesso à Universidades públicas e de qualidade em localidades distantes e isoladas, objetivando também incentivar o desenvolvimento de municípios com baixo Índice de Desenvolvimento Humano (IDH) e Índice de Desenvolvimento da Educação Básica (IDEB).
Nesse contexto, julga-se interessante conhecer as características dos alunos formados em regiões onde o acesso à educação é potencialmente mais dificultado, ou seja, em regiões interioranas do Brasil, onde, historicamente, as condições de acesso ao ensino superior público e gratuito são precárias. Desta forma, a contribuição dessa pesquisa reside em fornecer subsídios empíricos que contribuam para o desenvolvimento de ações de gestão e pedagógicas convergentes com o perfil dos alunos dessas regiões, capazes de melhorar o processo de ensino-aprendizagem e diminuir a evasão educacional nessas localidades.

Para o alcance desse objetivo, o artigo foi dividido em quatro seções, além dessa introdução. Primeiro, levantamos informações acerca da história da educação a distância e do perfil dos alunos que costumam ingressas nessa modalidade de ensino. Após, apresentamos os procedimentos e métodos adotados na pesquisa. A quarta sessão foi dedicada a apresentação dos resultados do perfil dos alunos de regiões mais afastados dos centros urbanos. Por fim, a quinta e última sessão reúne as conclusões encontradas.

\section{Fundamentação Teórica}

Nesta seção serão apresentados os principais referenciais teóricos que sustentam a presente pesquisa, a começar pela temática da educação a distância, sua origem e conceitos, e, em seguida, será abordado a Universidade Aberta do Brasil e o curso de Administração a distância da Universidade Federal de Santa Catarina. 


\section{A Educação à Distância}

A educação a distância, ao contrário do que possa parecer, não é fenômeno exclusivo da era digital. A sua origem e data de séculos atrás e está relacionada com os cursos realizados por meio do serviço de correios (MOORE; KEARSLEY, 2012) e o seu progresso possui estreita relação com a demanda da Revolução Industrial por uma mão-deobra formalmente educada (SUMNER, 2000).

O surgimento de novas tecnologias da comunicação e informação vem influenciando os formatos por meio dos quais a educação a distância se apresenta ao longo dos anos (ANDERSON; DRON, 2011). Se por algum tempo ela esteve atrelada à correspondência e à televisão, atualmente se destaca pelo uso de computadores e da internet.

Portanto, podemos compreender a educação a distância como "um sistema tecnológico de comunicação bidirecional", que, por meio da ação e interação de diferentes recursos didáticos e do suporte oferecido por uma organização e tutoria, é capaz de substituir a interação pessoal entre professor e alunos em sala de aula, como forma preferencial de ensino, e proporcionar aos estudantes uma "aprendizagem independente e flexível" (ARETIO, 1994, p. 14).

Simonson (2006) pontua alguns aspectos relevantes que caracterizam a educação a distância, dentre os quais pode-se destacar que ela é ancorada em uma instituição, o que a difere do autoestudo, existe a separação de espaço e tempo entre os atores envolvidos no processo de ensino aprendizagem, tais como professor, tutores e alunos, e utiliza tecnologias de interação capazes de integrar alunos, professor e recursos didáticos.

Para além das especificidades em seu formato, a educação a distância apresenta, na perspectiva de alguns autores, aspectos que a distinguem da educação tradicional quanto aos seus propósitos e o público a que se destina. Segundo Holmberg (apud SIMONSON, 2006) a criação de muitas instituições do ensino esteve relacionada com argumentos políticos e econômicos que davam conta da necessidade de expandir o acesso ao ensino superior, especialmente para um público que, por diferentes motivos, encontra barreiras para realizar um curso superior em instituições presenciais.

$\mathrm{Na}$ perspectiva de Rodriguez e Caro (2002), a educação a distância busca responder à problemáticas para as quais o ensino presencial não é capaz de fornecer soluções eficientes. Dentre elas, os autores destacam a questão geográfica, que impede, por vezes, que pessoas residentes em áreas remotas tenham acesso à educação. Neste caso, "o princípio da igualdade de oportunidades é ferido nesses indivíduos que geralmente vivem em áreas rurais de baixa densidade populacional" (RODRIGUEZ; CARO, 2002, p. 2). Para além disso, mesmo nos grandes centros urbanos, a distância geográfica pode ser um empecilho para o acesso ao ensino presencial, pois pode envolver elevados custos de deslocamento.

$\mathrm{O}$ ensino tradicional requer que professores e alunos compartilhem o mesmo tempo e espaço, o que pode ser um grande impeditivo, uma vez que os horários disponíveis de um indivíduo podem ser incompatíveis com os horários de funcionamento de uma instituição de ensino presencial. Ademais, alguns alunos apenas possuem os dias não úteis para a realização dos estudos ou tem os seus horários subordinados aos compromissos familiares e domésticos (RODRIGUEZ; CARO, 2002).

Uma última questão relacionada pelos autores se refere à problemas relacionados a demanda formativa, uma vez que em regiões onde a procura por cursos superiores não é suficiente para justificar um investimento surgem dificuldades para a oferta de formação, ainda que haja uma visível necessidade local (RODRIGUEZ; CARO, 2002).

Assim sendo, na visão de Pacheco (2010), os principais benefícios da educação a distância residem na possibilidade de flexibilizar os horários de 
estudo, a não necessidade de deslocamentos diários e compatibilização entre estudos e rotina familiar e laboral. Tendo em vista que, segundo Aretio (1997), os alunos a distância são caracterizados, geralmente, por heterogeneidade de faixa etária, competências e localização geográfica, indivíduos já inseridos no mercado de trabalho, que tem os estudos como atividade secundária e os realizam em casa ou no trabalho.

No Brasil, umas das principais iniciativas para a implementação da educação a distância na educação superior pública e gratuita ocorreu por meio da criação da Universidade Aberta do Brasil, que será apresentada na seção a seguir.

\section{A Universidade Aberta do Brasil e o Curso de Administração a Distância da Universidade Federal de Santa Catarina}

O Sistema Universidade Aberta do Brasil foi desenvolvido em 2005 pelo Ministério da Educação em parceria com a Associação Nacional dos Dirigentes das Instituições Federais de Ensino Superior e com empresas estatais no contexto do Fórum das Estatais pela Educação com foco nas Políticas e a Gestão da Educação Superior. A criação desse sistema objetivou a expansão do ensino em nível superior, no escopo do Plano de Desenvolvimento da Educação, por meio de uma política pública que integra e articula ações entre a Secretaria de Educação a Distância - SEED/MEC e a Diretoria de Educação a Distância - DED/CAPES (CAPES, 2015a).

A Universidade Aberta do Brasil se constitui por um "sistema integrado por Universidades públicas que oferece cursos de nível superior para camadas da população que têm dificuldade de acesso à formação universitária, por meio do uso da metodologia da educação a distância" (CAPES, 2015b).

De acordo com o Decreto 5.800, de 8 de junho de 2006, a UAB foi instituída com objetivo de fomentar "o desenvolvimento da modalidade de educação a distância, com a finalidade de expandir e interiorizar a oferta de cursos e programas de educação superior no país" (CAPES, 2015b).

Segundo a CAPES (2015b), a Universidade Aberta desempenha os seguintes papéis:

Fomenta a modalidade de educação a distância nas instituições públicas de ensino superior, bem como apoia pesquisas em metodologias inovadoras de ensino superior respaldadas em tecnologias de informação e comunicação. Além disso, incentiva a colaboração entre a União e os entes federativos e estimula a criação de centros de formação permanentes por meio dos polos de apoio presencial em localidades estratégicas.

O sistema da Universidade Aberta do Brasil está ancorado em alguns eixos principais, a saber:

\begin{abstract}
Expansão pública da educação superior, considerando os processos de democratização e acesso; aperfeiçoamento dos processos de gestão das instituições de ensino superior, possibilitando sua expansão em consonância com as propostas educacionais dos estados e municípios; avaliação da educação superior a distância tendo por base os processos de flexibilização e regulação implantados pelo MEC; estímulo à investigação em educação superior a distância no país; financiamento dos processos de implantação, execução e formação de recursos humanos em educação superior a distância (CAPES, 2015b).
\end{abstract}

A iniciativa acredita que a atuação das universidades públicas em regiões remotas pode contribuir para o desenvolvimento de localidades com baixo Índice de Desenvolvimento Humano (IDH) e de Desenvolvimento da Educação Básica (IDEB), ao desempenhar um papel voltado para "a universalização do acesso ao ensino superior e para a requalificação do professor em outras disciplinas, fortalecendo a escola no interior do Brasil, minimizando a concentração de oferta de cursos de 
graduação nos grandes centros urbanos e evitando o fluxo migratório para as grandes cidades" (CAPES, 2015b).

Nesse contexto surgiu o curso de administração a distância oferecido pela Universidade Federal de Santa Catarina (UFSC), instituição fundada no ano de 1960 e considerada uma das melhores instituições de ensino superior do Brasil e da América Latina (PACHECO, 2010). A UFSC possui campus em cinco cidades do estado de Santa Catarina, nomeadamente em Florianópolis (campus central da instituição), Blumenau, Araranguá, Curitibanos e Joinville (UNIVERSIDADE FEDERAL DE SSANTA CATARINA, 2015).

De acordo com Pacheco (2010, p. 184), o curso de graduação em administração, na modalidade a distância da UFSC foi criado:

[,,,] em resposta à demanda motivada pelo Ministério de Educação, com a finalidade de atender às necessidades das empresas estatais em termos de qualificação dos seus servidores públicos, a Universidade Federal de Santa Catarina - UFSC, juntamente com outras instituições de ensino superior, participou do projeto de criação do Curso de Graduação em Administração, na modalidade a distância, como um programa da Universidade Aberta do Brasil - UAB/MEC.

Salienta-se que o curso de graduação em administração na forma presencialé tradicionalmente oferecido pela instituição, que adotou a modalidade a distância em resposta a necessidade de atender alunos provenientes de regiões com acesso ao ensino superior público dificultado e, também, profissionais em serviço que necessitam de formação em nível universitário (PACHECO, 2010).

Até o momento foram concluídos dois projetos pilotos e uma edição do curso. Outras três edições encontram-se em andamento. Nesse âmbito, foram diplomados mais de 600 alunos e uma parcela significativa está cursando a graduação.

\section{Metodologia}

Os procedimentos metodológicos adotados nessa pesquisa obedecem a uma orientação quantitativa, que se caracteriza pela utilização de dimensões quantificáveis nos processos de coleta de dados e pelo uso de técnicas estatísticas para o seu tratamento (SOUZA; FIALHO; OTANI, 2007). Desta forma, utilizou-se a técnica de levantamento de dados, também denominada de survey, que é uma investigação em que se coleta dados para descrever e estimar as características de uma determinada população, por meio de técnicas estatísticas (OECDE, 2016).

Para atender o objetivo desta pesquisa, foram escolhidas localidades que não se caracterizam como grandes centros urbanos, pois anseia-se perceber a atuação da educação a distância onde ela é potencialmente mais relevante, em território com o acesso ao ensino superior público limitado. A pesquisa compreende os alunos diplomados entre os anos de 2010 e 2014. Isto porque os primeiros bacharéis do curso de administração da Universidade Federal de Santa Catarina datam do ano de 2010. A limitação no ano de 2014 ocorreu devido ao fato da pesquisa de campo ter iniciado em 2015. Este recorte delimitou o universo de pesquisa a 132 alunos. Destes, 53 estudaram em polos catarinenses ( 25 na cidade de Laguna e 28 em Tubarão) e 79 no estado do Rio Grande do Sul (13 em São Francisco de Paula, 19 em Tapejara, 21 em Tio Hugo e 26 em Jacuizinho).

O instrumento de coleta de dados utilizado nessa pesquisa foi o questionário. O questionário foi construído e alojado na plataforma Google Forms, que registra os dados em documento em planilhas virtuais. Partindo dos dados de contato dos alunos fornecidos pela secretaria do curso de administração a distância da Universidade Federal de Santa Catarina, foram realizados contatos intervalados via e-mail, contato telefônico e envio de mensagens via telefone e Facebook com o intuito obter respostas às respostas dos inquéritos. 
Desta forma, obteve-se uma taxa de respostas de $47,7 \%$, ou seja, 63 questionários respondidos. Ressalta-se que o inquérito foi desenvolvido em consonância com uma pesquisa de levantamento da Universidade Aberta de Portugal, e, assim sendo, foram inseridas, retiradas e modificadas questões no conjunto da pesquisa, para que os dados pudessem se adaptar à realidade brasileira.

Para a análise dos dados, optou-se pelo uso da estatística descritiva, que se baseia na soma dos dados e criação de ferramentas de análises, tais como gráficos e tabelas (HUOT, 2002; REIS, 1996). Como suporte para a análise dos dados quantitativos, recolhidos mediante a aplicação de questionários, foi utilizado o software SPSS, versão 22. O tratamento dos dados estatísticos recorreu-se a uma análise descritiva simples, apresentada por meio de gráficos.

Particularmente nessa pesquisa analisou-se sete critérios: a) Gênero; b) Idade; c) Estado Civil; d) Escolaridade antes do ingresso; e) Ocupação no momento da graduação; f) profissão no momento de entrada no curso; g) Experiência no ensino superior, anterior ao curso; e h) Local mais utilizado para estudar.

\section{Análise dos Dados}

Na seção de análise dos dados será apresentada inicialmente uma breve descrição dos indicadores educacionais das localidades estudadas, a começar pelos dados do estado do Rio Grande do Sul e, depois, de Santa Catarina. Em seguida, será apresentada a caracterização dos diplomados na seguinte ordem: pessoal, profissional e acadêmica.

\section{Indicadores das localidades estudadas}

Como referido no capítulo metodológico, as localidades foram escolhidas com base no critério dos índices de educação superior. No caso das cidades do estado do Rio Grande do Sul, verificou-se que todos os municípios estudados apresentam índices inferiores aos valores em âmbito estadual e nacional. Essa diferença torna-se ainda maior quando esses índices são comparados com a capital do estado, Porto Alegre, tendo em vista que o município com melhor índice de educação superior (Tapejara: 9,6\%) está 16,25 pontos percentuais abaixo do índice da capital $(25,9 \%)$, ou seja, menos que a metade do valor encontrado em Porto Alegre. As outras cidades ficaram com os seguintes valores do percentual de pessoas com ensino superior: Tio Hugo com 4\%, São Francisco de Paula com 5,7\% e Jacuizinho com 6,1\% (RIO GRANDE DO SUL, 2015).

No estado de Santa Catarina o panorama é semelhante, uma vez que os municípios estudados apresentam uma desvantagem percentual relativamente à parcela da população com ensino superior quando comparados com a capital do estado. Na cidade de Tubarão, verificou-se que $14,6 \%$ de sua população possui ensino superior, superando timidamente a taxa estadual $(12,5 \%)$ e a nacional (11,3\%). Entretanto, comparada com a capital, Florianópolis, existe um grande déficit em sua taxa, sendo inferior na grandeza de 16,82 pontos percentuais, ou seja, menos da metade do valor encontrado na capital. Já a cidade de Laguna possui somente $7,9 \%$ de sua população com ensino superior (SANTA CATARINA, 2015).

\section{Caracterização pessoal}

Iniciando a caracterização dos diplomados é possível constatar que, em termos etários, a parcela mais significativa deles encontra-se entre os 30-40 anos e a média de idade é de 34,9 anos (ver Gráfico 1). Essa faixa etária é maior que a encontrada em cursos presenciais. Segundo dados do Censo da Educação Superior, de 2013, os diplomados em cursos de nível superior presenciais possuem, em média, 28,1 anos, enquanto na modalidade a distância, esse número passa para 35,7 anos (INSTITUTO NACIONAL DE ESTUDOS E PESQUISAS EDUCACIONAIS ANÍSIO TEIXEIRA, 2013). Assim sendo, o curso 
de Administração da Universidade Aberta do Brasil/UFSC segue os mesmos padrões dos cursos a distância, em âmbito nacional, e atende a uma parcela da população com idade mais elevada.

Gráfico 1 - Faixa etárias dos inquiridos - UAB/UFSC

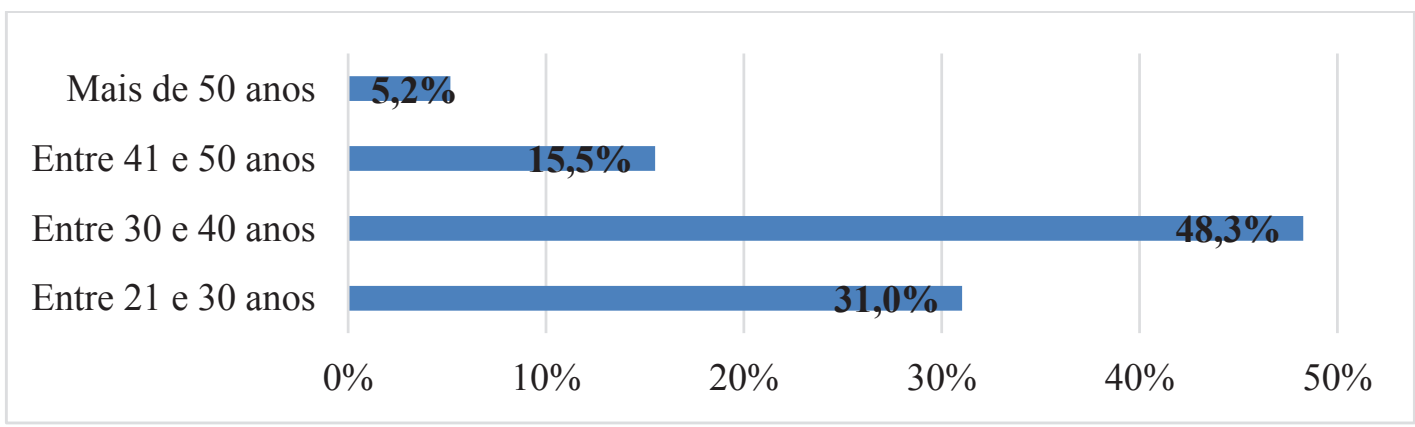

Fonte: Elaborado pelos autores.

Relativamente ao gênero, verifica-se um equilíbrio na amostra pesquisa, na qual $51 \%$ dos respondentes são do sexo feminino e $49 \%$ do sexo masculino. Esse resultado aponta indícios a respeito da equidade de gênero no curso de Administração da Universidade Aberta do Brasil. Ressalta-se que o percentual de mulheres é um pouco abaixo do encontrado em estudos semelhantes da política da $\mathrm{UAB}$, em que $56,5 \%$ das inquiridas eram do sexo feminino (PEREIRA; PACHECO; FIATES, 2013).

No que se refere ao estado civil, constata-se a predominância de pessoas casadas ou com união estável, totalizando $65,1 \%$ da amostra, sendo que
$30,2 \%$ das pessoas declararam ser solteiras (ver Gráfico 2). Em pesquisa realizada pela ANDIFES (2011), sobre o perfil socioeconômico e cultural dos estudantes de graduação das universidades federais brasileiras, revelou-se que, na modalidade presencial, o universo de estudantes solteiros é de $86,6 \%$. A diferença encontrada quanto a situação conjugal dos estudantes, demonstra mais um aspecto característico dos alunos na modalidade a distância, no qual a condição familiar, assim como profissional, é diferenciada e pode interferir na vida acadêmica de forma distinta.

Gráfico2 - Estado civil dos inquiridos - UAB/UFSC

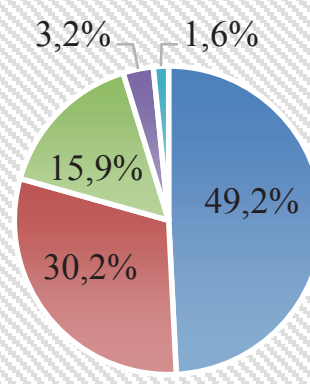

- Casado(a)

- Solteiro(a)

- União estável

- Viúvo(a)

- Divorciado(a)

Fonte: Elaborado pelos autores 
No momento de ingresso no curso, os dados relativos à escolaridade revelaram que mais da metade (54\%) dos indivíduos detinha apenas o ensino médio (ver Gráfico 3). Tendo em vista, que o perfil estudado indicou uma média etária elevada, comparativamente ao ensino presencial, é possível que esses alunos estivessem afastados do âmbito escolar por espaço de tempo, uma vez que a continuidade dos estudos, sem interrupção, acarretaria na formação superior por volta dos 23 anos de idade.

Gráfico 3 - Escolaridade antes do ingresso no curso - UAB/UFSC

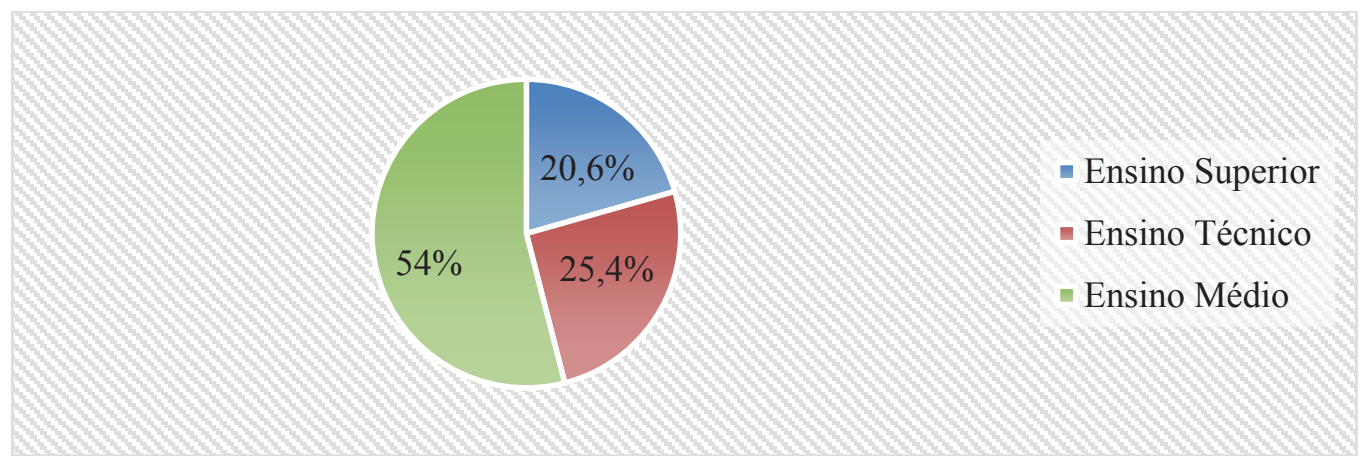

Fonte: Elaborado pelos autores.

\section{Caracterização profissional}

Analisando a ocupação dos diplomados durante o curso, é clara a predominância de pessoas que trabalhavam em tempo integral $(93,7 \%)$, sendo que outros $3,2 \%$ estavam a trabalhar em tempo parcial e
$1,6 \%$ não estavam a trabalhar, mas dedicavam-se a cuidar de filhos ou outros familiares. Somente 1,6\% dos diplomados estava dedicado a tempo integral aos estudos (ver Gráfico 4).

Gráfico 4 - Ocupação durante a graduação na UAB/UFSC

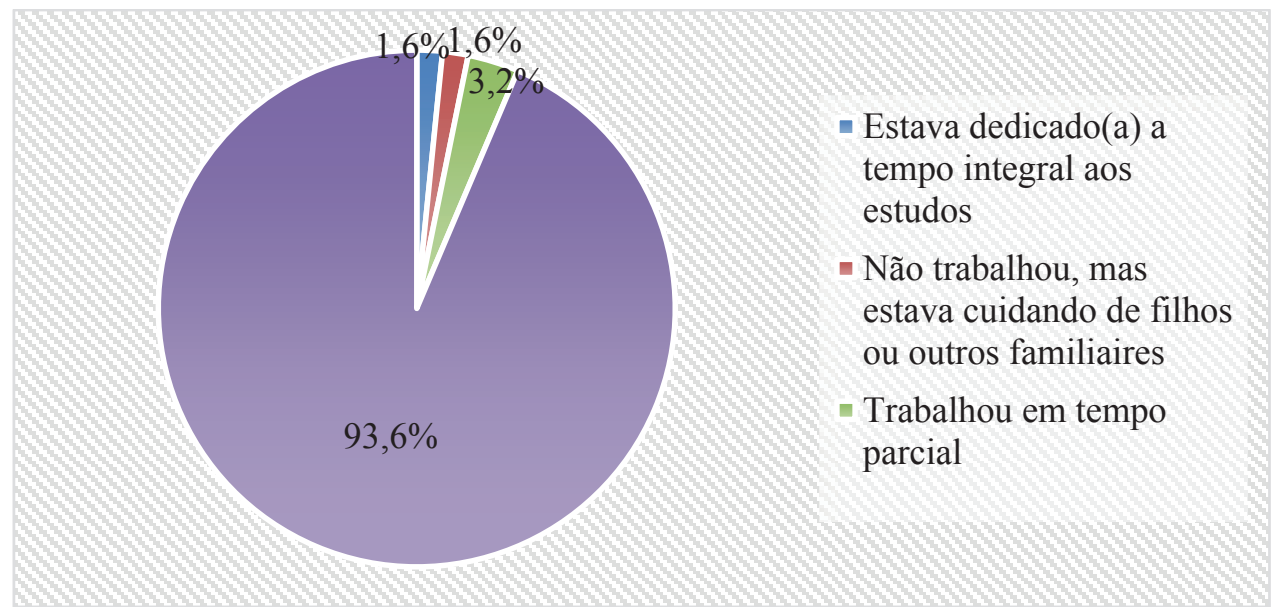

Fonte: Elaborado pelos autores. 
Dentre os alunos que desempenham atividades de nível médio e trabalhadores do comércio e profissionais, a grande maioria é formada por serviços (ver Gráfico 5).

trabalhadores de serviços administrativos, técnicos

Gráfico 5 - Profissão no momento de entrada no curso na UAB/UFSC.

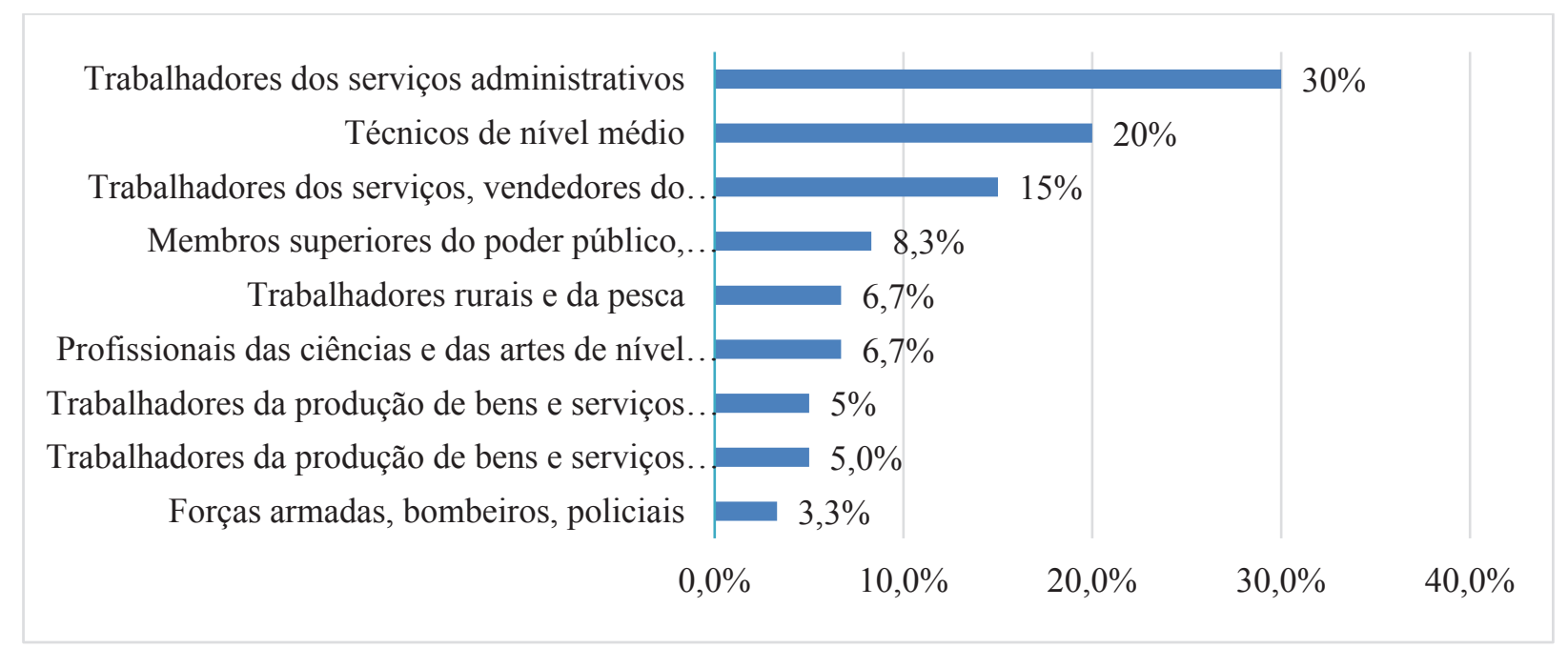

Fonte: Elaborado pelos autores.

Esses dados permitem novamente delinear alguns traços característicos dos alunos a distância, compostos, predominantemente, por pessoas já inseridas no mercado de trabalho e que precisam conciliar a vida profissional com a familiar. No caso dos alunos presenciais, o percentual de trabalhadores é de 37,6\%, em âmbito nacional. Na região sul, onde estão localizados os polos de ensino e, consequentemente, a grande maioria dos alunos pesquisados, esse número sobe para $46,3 \%$, mas permanece significativamente menor, quando comparado à educação a distância (ANDIFES, 2011).

\section{Caracterização acadêmica}

Relativamente a experiência no ensino superior antes da realização da graduação na UAB-UFSC, $46 \%$ dos indivíduos afirmaram nunca ter frequentado o ensino superior. Dentre os que disseram já ter concluído um curso superior $(22,2 \%), 3,2 \%$ o realizam na UAB (ver Gráfico 6). 
Gráfico 6 - Experiência no ensino superior antes da graduação na UAB-UFSC

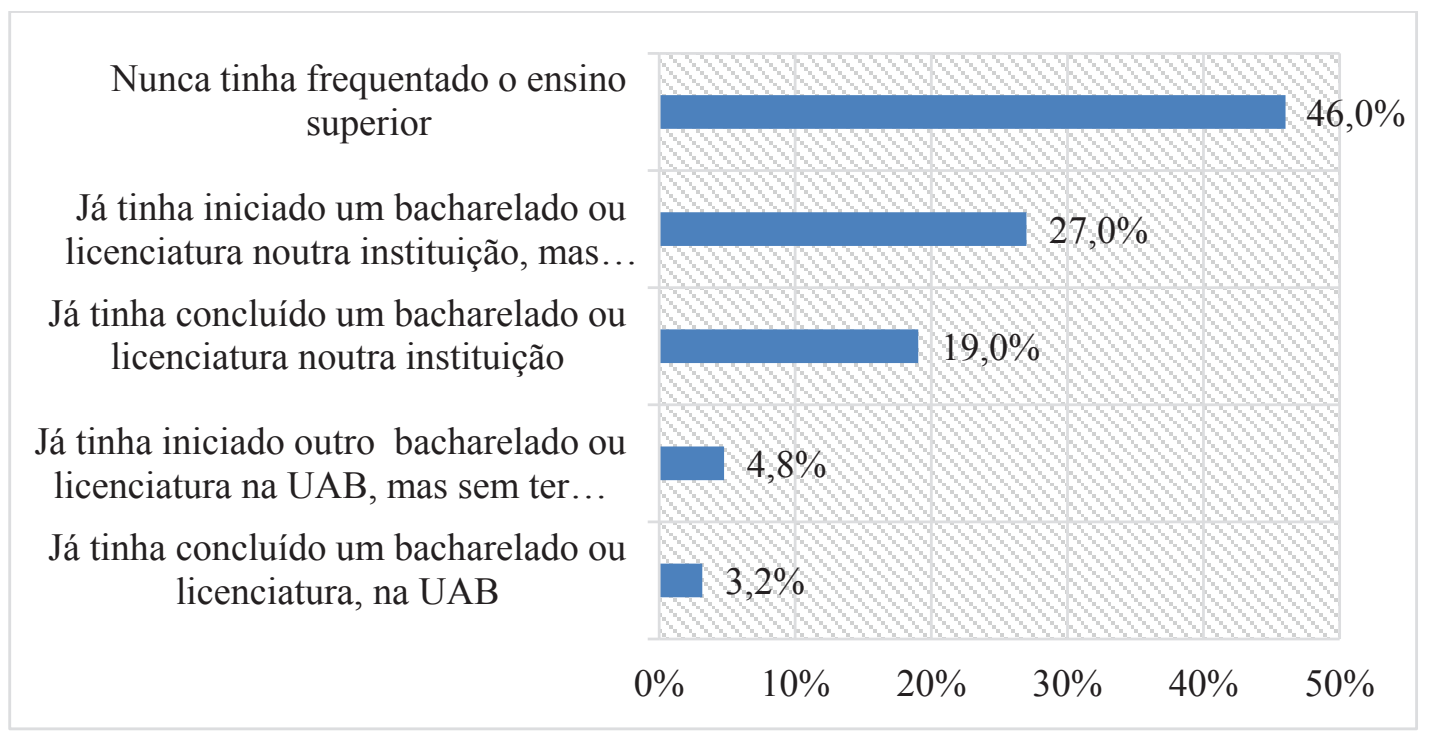

Fonte: Elaborado pelos autores.

No que se refere ao local de realização das atividades do curso, verifica-se que a grande parte dos indivíduos utiliza a própria casa para realização de suas tarefas acadêmicas $(88,9 \%$ ) (ver Gráfico 7$)$.
Tendo em vista a situação laboral e conjugal dos inquiridos, nota-se uma possível implicação das atividades acadêmicas em âmbito familiar.

Gráfico 7 - Local de realização das atividades do curso da UAB-UFSC

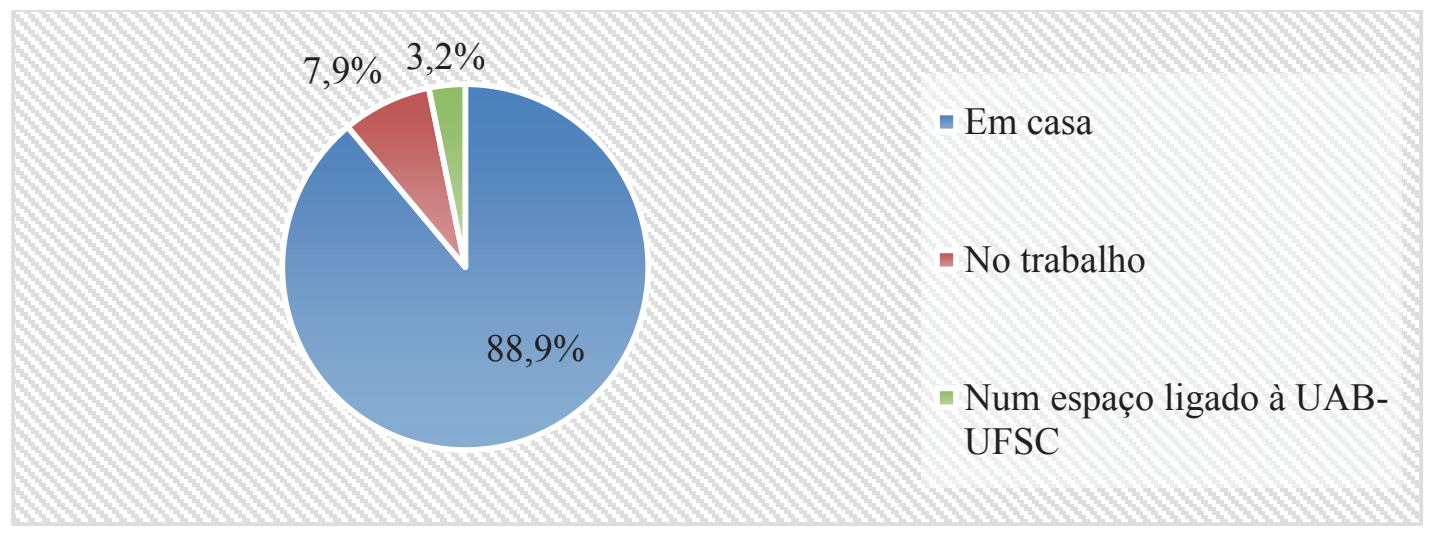

Fonte: Elaborado pelos autores. 
É relevante ressaltar que somente uma pequena parcela (3,2\%) utilizou um espaço ligado à Universidade. Isto indica que o espaço destinado ao estudo dos alunos nos polos de ensino é pouco utilizado. Assim sendo, julga-se interessante que os envolvidos na gestão dos polos de ensino averiguem os motivos da não utilização desses espaços para estudo, que podem estar relacionados a não adequação de seus horários de funcionamento com as necessidades dos alunos, localização, estrutura física, dentre outros aspectos.

\section{Considerações Finais}

Em linhas gerais, os diplomados aqui pesquisados são compostos predominantemente, por pessoas entre os 30-40 anos, casadas ou com união estável. A grande maioria ainda não tinha concluído um curso superior e trabalhou durante a graduação.

Segundo dados do Censo da Educação Superior, de 2013, realizado no Brasil, os diplomados em cursos de nível superior presenciais possuem, em média, 28,1 anos, enquanto esse número passa para 35,7 anos na modalidade a distância (INSTITUTO NACIONAL DE ESTUDOS E PESQUISAS EDUCACIONAIS ANÍSIO TEIXEIRA, 2013). Assim sendo, o curso de administração da Universidade Aberta do Brasil/UFSC segue os mesmos padrões dos cursos em geral, em âmbito nacional, e atende a uma parcela da população em faixas etárias mais elevadas.

Em pesquisa realizada pela ANDIFES (2011), sobre o perfil socioeconômico e cultural dos estudantes de graduação das Universidades Federais brasileiras revelou que, na modalidade presencial, o universo de estudantes solteiros é de $86,6 \%$, enquanto na pesquisa aqui realizada apenas $30,2 \%$ possuem este perfil conjugal. Ressalta-se também que o percentual de trabalhadores na modalidade de ensino presencial é significativamente menor (37,6\%) quando comparada aos alunos a distância pesquisados $(96,9 \%)$.
As diferenças encontradas demonstram aspectos característicos dos alunos na modalidade a distância, no qual a condição familiar, assim como profissional, é diferenciada e pode interferir na vida acadêmica de forma distinta. Isto quer dizer que são alunos mais velhos e com vida familiar e profissional mais avançada do que os presenciais e, portanto, precisam conciliar os estudos, família e trabalho.

Outra questão a ser ressaltada é que os alunos não possuíam ensino superior antes de entrar no curso a distância oferecido pela UFSC. Esses dados dão indicativos de que a educação a distância cumpre, neste contexto, a função de atender um público que, por diferentes motivos, não consegue aceder ao ensino superior presencial (RODRIGUEZ; CARO, 2002) e, desta forma, apresenta potencial para influenciar positivamente as sociedades que a abrigam e impulsionar o seu desenvolvimento.

Portanto, políticas como as da Universidade Aberta do Brasil podem ser importantes para o desenvolvimento de regiões interioranas do país e, para que ocorra um processo de implementação adequado de cursos, que atendam a demanda das comunidades, deve-se analisar cuidadosamente as características do público local.

\section{Referências}

ANDERSON, T.; DRON, J. Three generations of distance education pedagogy. International Review of Research in Open and Distance Learning, Canadá, v. 12, n. 3, p. 8097, 2011. Disponível em: <http://www.irrodl.org/index. php/irrodl/article/view/890>. Acesso em: 5 dez. 2014.

ANDIFES. Perfil Socioeconômico e Cultural dos Estudantes de Graduação das Universidades Federais Brasileiras. Fórum nacional de pró-reitores de assuntos comunitários e estudantis - (FONAPRACE). Brasília, 2011.

ARETIO, L. G. Educacion a distancia hoy. Madri: Universidad Nacional de Educación a Distancia, 1994.

. La enseñanza abierta a distancia como respuesta eficaz para la formación laboral. 1997. Disponível em: $<$ http://e-spacio.uned.es/fez/eserv/bibliuned:20199/ ensenanza_abierta.pdf $>$. Acesso em: 5 abr. 2015. 
ASSOCIAÇÃO BRASILEIRA DE EDUCAÇÃO A DISTÂNCIA. Censo EAD.BR: relatório analítico da aprendizagem a distância no Brasil. 2015. Disponível em: <http://abed.org.br/arquivos/Censo_EAD_2015 POR.pdf>. Acesso em: 5 maio 2016.

CAPES. Histórico. Disponível em: <http://www.capes. gov.br/component/content/article?id=7838>. Acesso em: 5 maio 2015 a.

O que é UAB? Disponível em: <http://www. capes.gov.br/component $/$ content $/$ article? $\mathrm{id}=7836>$. Acesso em: maio/2015b.

FERREIRA, Z. N.; MENDONÇA, G. A. A.; MENDONÇA, A. F. O perfil do aluno de educação a distância no ambiente teleduc. In: CONGRESSO INTERNACIONAL DE EDUCAÇÃO A DISTÂNCIA, 3., 2007, Curitiba. Anais... Curitiba, 2007. Disponível em: $\quad<$ http://www.abed.org.br/congresso2007/ tc/417200794130AM.pdf $>$. Acesso em: 30 jan. 2017.

HUOT, R. Métodos quantitativos para as ciências humanas. Lisboa: Instituto Piaget, 2002.

INSTITUTO NACIONAL DE ESTUDOS E PESQUISAS EDUCACIONAIS ANÍSIO TEIXEIRA. Censo da educação superior 2013. Disponível em: $<$ http://download.inep.gov.br/educacao_superior/ censo_superior/apresentacao/2014/coletiva_censo_ superior_2013.pdf>. Acesso em: 2 maio 2015.

MOORE, M. G.; KEARSLEY, G. Distance education: a systems view of online learning. New York: Cengage Learning, 2012.

OECDE - ORGANISATION FOR ECONOMIC COOPERATION AND DEVELOPMENT. Statistics Portal. Glossary of Statistical Terms. Survey. Disponível em: $<$ https://stats.oecd.org/glossary/detail.asp?ID $=2620>$. Acesso em: 20 jul. 2016.

PACHECO, A. S. V. Evasão e permanência dos estudantes de um curso de administração do sistema Universidade Aberta do Brasil: uma teoria fundamentada em fatos e na gestão do conhecimento. 2010. Tese (Doutorado em Engenharia e Gestão do Conhecimento) - Universidade Federal de Santa Catarina, Florianópolis, 2010.
PACHECO, A. S. V. et al. Evasão e permanência dos estudantes de um curso de administração do sistema Universidade Aberta do Brasil: uma teoria multiparadigmática. In: ENCONTRO DE ENSINO E PESQUISA EM ADMINISTRAÇÃO E CONTABILIDADE, 3., João Pessoa, 2011. Anais... João Pessoa: EPQ, 2011. p. 1-17.

PEREIRA, A. R.; PACHECO, A. S. V.; FIATES, G. G. S. Perfil dos egressos do curso de Administração EaD/ UFSC/UAB e a consonância com a política educacional de EaD. In: COLÓQUIO LUSO-BRASILEIRO DE EDUCAÇÃO A DISTÂNCIA E ELEARNING, 3., 2013, Lisboa. Anais... Lisboa, 2013.

REIS, E. Estatística descritiva. Lisboa: Sílabo, 1996.

RIO GRANDE DO SUL. In: ATLAS DO DESENVOLVIMENTO HUMANO NO BRASIL. Disponível em: <http://www.atlasbrasil.org.br/2013/pt/ perfil_uf/43\#educacao>. Acesso em: 5 dez. 2015.

RODRIGUEZ, A. G.; CARO, E. M. La formación permanente y el e-learning: la experiência de los ingenieros de minas de España. Virtual Educa, Valencia, 2002. Disponível em: <http://www.virtualeduca.org/ virtualeduca/virtual/actas2002/actas02/1009.pdf > . Acesso em: 5 jan. 2014.

SANTA CATARINA. In: ATLAS DO DESENVOLVIMENTO HUMANO NO BRASIL. Disponível em: <http://www.atlasbrasil.org.br/2013/pt/ perfil_uf/42\#educacao>. Acesso em: 5 dez. 2015.

SIMONSON, M. Teoría, investigación y educación a distancia. In: BARBERÀ, E. Educación abierta y a distancia. Barcelona: UOC, 2006.

SOUZA, A. C.; FIALHO, F. A. P.; OTANI, N. TCC: métodos e técnicas. Florianópolis: Visual Books, 2007.

SUMNER, J. Serving the system: a critical history of distance education. Open Learning, Essex, v. 15, n. 3, p. 267-285, 2000.

UNIVERSIDADE FEDERAL DE SANTA CATARINA. Campi. Disponível em: <http://estrutura.ufsc.br/campi/>. Acesso em: 5 maio 2015. 